\title{
Ethical Issues in Communicating Science
}

\author{
Jinnie M. Garrett · Stephanie J. Bird
}

\section{Erratum to: Sci Eng Ethics (2007) 13:99-115 \\ DOI: $10.1007 / \mathrm{s} 11948-000-0001-7$}

Unfortunately, a mistake has been made in the names and affiliations of the authors of this article. Please find below the correct information:

Jinnie M. Garrett ${ }^{1}$ and Stephanie J. Bird ${ }^{2}$

${ }^{1}$ Department of Biology, Hamilton College, 13323 Clinton, New York, USA

2 Massachusetts Institute of Technology, Room 12-188, 77 Massachusetts Avenue, 02139 Cambridge, MA, USA

The online version of the original article can be found under doi:10.1007/s11948-000-0001-7

J. M. Garrett $(\bowtie)$

Department of Biology, Hamilton College, Clinton, New York 13323, USA

e-mail: jgarrett@hamilton.edu

\section{S. J. Bird}

Massachusetts Institute of Technology, Room 12-188, 77 Massachusetts Avenue,

Cambridge, MA 02139, USA 